\title{
RETENTION AND COURSE CHOICE IN DISTANCE LEARNING
}

\author{
Ormond Simpson, United Kingdom Open University
}

\section{Introduction}

It is a widely held view that that process of course choice is an important factor in new students' subsequent retention or dropout - see for example McGivney (1996). A student making an inappropriate choice - either the wrong level of course for them or the wrong content - is thought much more likely to dropout than a student who is on a course for which they are suited by both level and content.

Amongst distance education students some clear evidence comes from the annual survey of withdrawn students in the UKOU Institute of Educational Technology (2002). In this survey 'inadequate course choice guidance' is the second most chosen item after 'insufficient time' as reason for withdrawn students' greatest dissatisfaction - some $21 \%$ are dissatisfied with this aspect of their studies.

\section{Making course choice decisions}

Students can make course choice decisions using various materials such as course titles and descriptions, guidance, other students' opinions and 'taster' materials.

\section{Course titles and descriptions}

Most distance students will decide on their course choice from the course descriptions provided by the institution. There are a number of issues around such titles and descriptions:

- Length. If descriptions are short then they are likely to be incomplete in some respects or at least to lack comprehensiveness especially in the case of long courses covering considerable ground. Long descriptions may be relatively impenetrable.

- Vocabulary. The vocabulary available to course description authors may be inherently imprecise. Authors often use terms such as 'explore', 'describe', 'advanced', 'elementary' and so on which allow for wide interpretations by the intending student. Even where descriptions are written in terms of outcomes these may not be clear to students who may not understand an outcome stated in unfamiliar terms. It may be little help knowing that a course will give a 'thorough understanding of vector algebra' if students have only a very hazy idea as to what vector algebra is.

- Conflict between recruitment and retention (Simpson 2003). A course description may be written with the subsidiary aim of encouraging recruitment onto a course. In such cases there may be a conscious or unconscious temptation to emphasise the accessibility of the course at the expense of its difficulty.

- Assumed entry behaviour. Course descriptions can specifically address potential students' entry requirements both in terms of the previous knowledge assumed and the skills required and this may be one of their most valuable functions. However knowing that a course assumes potential students have a particular previous qualification does not tell them that it is definitely suitable for them nor does it help students who do not have that qualification but who might be able to study the course.

It may not be enough therefore to rely solely on course descriptions for getting students onto the best course for them. 


\section{Course choice guidance.}

The most obvious route to ensuring that students get the right course for them is to offer them advice from a course choice adviser. However again there are a number of issues around this approach:

- One to one advice is expensive for an institution to provide, particularly in mass distance education. The UKOU has 35000 new students each year and a staff of around only 35 trained advisers. So it is inevitable that most new students will not be in a position to speak to an adviser at any length.

- Potential students may not find it easy to frame the questions they should be asking about a course. A skilled adviser can clarify but this can be a lengthy process.

- Advisers may have the generic skills to advise on course choice but not necessarily the detailed knowledge of a particular course to answer all the possible questions that might be asked. In that case processes of referral or information gathering may be needed which add to the cost and length of the process.

- Students in distance education often appear reluctant to seek advice. The proportion of students seeking course choice advice from an advisor by any route in the UKOU is probably only about $10 \%$ of the students choosing courses in any one year.

- There is evidence that even where students receive advice that they ignore it. Johnson (2000) reported on a follow-up of advice given to a number of UKOU students whose course choice appeared to be unsuitable. Although the advice had the effect of getting students to reduce the number of courses they were taking it did not usually make them change their course choice. Once having made their choices students were clearly committed to them.

- Finally access to guidance may be difficult for some students - as Clayton and Mcgill (2000) note those who could most benefit from guidance are often the least able to access it for reasons of remoteness, unassertivness and so on.

Attention has therefore turned to alternative methods of providing course choice advice 'reflexively' that is a potential student 'self-advises' as a result of working through different kinds of materials. There are a number of different methods.

\section{Students' Comments on courses}

Potential students will value the views of students who have taken courses previously. This is not to say that students will be guided entirely by such views but that they are likely to be factors in students' decisions.

In 1996 some UKOU students who had recently taken courses were invited to write a short note (100200 words) aimed at advising new students considering taking the course they had just finished. These were lightly edited and collated into single sets for each course.

The comments are now supplied as hard copy and on the web - www.open.ac.uk/courseviews. Each of about 150 undergraduate courses has a set of comments - usually containing about ten or so individual comments from individual students thereby giving a number of alternative perspectives on the course. This is a typical comment for course A210 'Approaching literature, authors, readers and texts':

"A highly rewarding and stimulating course, but demanding in its reading requirement. An open mind is needed to make the most of the course. Those who resist the course's call to approach and explore literature in a variety of ways waste energy and miss out on some of its riches. Those who tackle the course in a positive way will find much that is both challenging and enjoyable, and have their literary horizons permanently widened."

There were initially some concerns that comments might be overly critical, negative or simply unfair. This has not turned out to be the case at all. There are negative comments but they are almost always in the context of a balanced opinion. For example it is not at all unusual for students to criticise the work load of a course as very heavy but add that providing one can handle that it is an exciting and 
worthwhile course. Indeed the overall tenor of the comments is usually very positive whilst realistic about the challenges that the courses represent.

\section{Evaluating the Students' Comments}

It is hard to assess the effectiveness of the Students' Comments in terms of ensuring that students make the best course choice for themselves. There are various evaluations however:

\section{- Site usage}

The site has steadily increased in popularity and 'hits' are running at around 850 a day.

\section{- Student and tutor feedback}

The site allows students and tutors to send feedback. This is consistently positive:

An example of feedback to the Student Comments website:

'An excellent idea! I wish it had been in place last autumn, it would have made my choice much easier I absolutely love this page and find it the most useful and interesting way to get a really good feel for the course and what is on offer. I shall soon compose and send my thoughts on a wonderful A103 year.'

Interestingly some of the comments suggest that students are using the site for preparatory advice as well as for course choice. This may mean that the Students' Comments have a particularly important role to play for new students.

\section{Students Comments - the political dimension}

This has always been a difficult project for the UKOU as in a typical recruitment versus retention dichotomy course teams are uneasy with the idea that students' comments on their courses can be seen so widely. Indeed in order to protect the project the originator arranged that it should come under the aegis of the Open University Students Union. Nonetheless the comments are still not linked from any of the UKOU's official course information web pages presumably because of uneasiness that such linking would provide an official imprimatur.

However the political environment is changing. Last year the Higher Education Funding Council for England and Wales produced a report ['Information on quality and standards in higher education' HEFCE 02/15 March 2002 informally known as the Cooke Report] which recommended that universities in the UK be required to publish information on the quality and standards of their teaching and learning. The information published should include the outcomes of student satisfaction surveys. This in turn was based on Australian practice which requires universities to place student feedback on the Web.

Subsequent to the report the HEFCE issued a circular to all UK universities in which it announced its intention to pilot a similar activity in the UK which would include student feedback ['Information on quality and standards: pilot of recommendations from the Cooke Report' HEFCE 04/2003, 7 February 2003]. There is a problem from Australia that response rates there were sometimes too small - some courses received only one or two comments thus potentially distorting the judgements. It is not clear how many comments are needed to give a fair judgement but the average number of about 10 comments on each course on the Students' Comments may be a good balance between fairness and overkill.

\section{Students' Comments - the costs}

To some extent student comments become now self generating as sites can be designed to allow students to send their own comments to a designated email address. They can then be edited and placed on the site. For the 200 or so courses on the UKOU website the annual costs amount to only about $£ 1500 \mathrm{pa}$. There is therefore a powerful case both in political and financial terms to maintain and develop the Students Comments. 


\section{Students Comments - live}

The use of computer conferencing can allow potential students to ask questions of experienced students directly on line. There is an example on the Bart's Medical School site where school students can post questions which are answered by current medical students:

\section{From Little-Samantha Status: Final Year School pupil (Y11) \\ Hi everyone,}

My boyfriend is interested in medicine, but seems to have a little phobia of the good ol' red stuff. Small amounts are ok (I think), but he watched a surgery programme on TV once and felt sick to his stomach. So to those med students (or anyone with work experience): have you ever felt a little squeamish, and how have you dealt with it? Is it something you all just get used to? Thanks a lot.

P.S. exams over with now. Just a long wait until August 22nd. ;-)

From tig Status: medical student (yr-3)

I can't watch surgery on tv..... in real life.. fine! on tv everything is distorted and I am very sqeamish!

From azy_cool Status: 1st Year Medical Student at Manchester

I was a little squeamish before I started, when looking at surgery on tv etc, but I used to watch it cos it was intresting and it got 'easier' to watch the more you watch it .. so he can try that, Operation comes on the Discovery channel most nights I think? In medicine having to cut up dead bodies .. that does sound quite bad, but really it was fine, even the first lesson was fine,

I think tig is right its much easier in real life then on tv ... if he really wants to do medicine then being squeamish shouldnt be a problem yet, Im sure he'll be fine when he starts.

\section{Students comments - the limitations}

Students' comments are of course limited in value. They cannot tell students that they have the right background for a course and they will always represent partial views of courses.

\section{Course Preview Materials - 'Taster Packs'}

Taster packs have a long history in distance education and early examples were produced by the National Extension College in the early 1980's. They were introduced by the author of this article in the UKOU in 1986 for the then foundation courses.

The original rationale was a simple one: students considering a particular course should have the opportunity of surveying the materials and undertaking a short 'test drive' of that course. The reasons for using specifically designed materials for the purpose were two-fold:

- Cost - in theory in distance education all the course materials are available in written form so there should be no barrier to potential students browsing through an entire course at leisure to see if it suits them. In practice the cost of sending an entire course would clearly be prohibitive and lending them is impossible in view of the number of potential students.

- Typicality - a complete UKOU course can consist of 30,000 words or more. Even if potential students could get their hands on a course it is clearly unfeasible to do anything more than read through a few of the pages of one of its constituent units. But then individual units may be untypical of the course as a whole.

It seemed better therefore to select short samples of the course which were thought to be reasonably typical. It was easy to add examples of assessment materials such as an assignment with a tutor's comments and grade and an exam paper in order to give students some kind of feel for the level of work they would have to produce at some point.

Once again there were recruitment versus retention concerns. For example it was thought that such packs would deter students from studying a course. In order to deal with this each pack came with an explanation of the pack's purpose and a 'health warning' pointing out that it might contain material that relied on knowledge gained earlier in the course. 
Of course the intention of such a pack is to deter students from taking a course if either the content is not relevant to their needs or at the wrong level. There would be cause for concern if it was found to be deterring students from a course that was right for them. In fact Adams et al (1989) found no evidence for that belief and student feedback was uniformly positive.

\section{Student feedback on taster packs}

These are selected at random from several hundred comments:

Interesting, informative. Challenges thoroughly paraded. Thanks for the health warning!

Excellent resource, certainly helped me in making the right decision for my future.

Very helpful-assisted in my decision to go ahead with this course this year.

Many thanks for the taster pack. I found it very interesting, giving an insight as to the work involved. Enough to prepare - enough to scare!

It is always difficult to evaluate such feedback as students who have negative responses may not bother to feed those back. But the uniformity of positive response is remarkable. The feedback reveals that potential students find the packs reassuring rather than off-putting. To a potential student a course represents an intimidating unknown and there must always be the question - 'can I cope?' To see a typical selection from a course and realise that although it may be challenging it is not completely unintelligible may overcome fear of that unknown.

\section{Course Preview materials - the cost}

One of the attractions of preview materials is that because they are derived from existing course materials they are inexpensive to produce. There are costs in deciding what selection of material should be used but these are one-off costs which can be amortised against the life of the course. Thus in the UKOU the editing cost of producing a Taster Pack for a course is around $£ 100$ and the reproduction costs are around $£ 1$ per pack. Thus Taster Packs may represent a cost-effective advisory method.

\section{Course Preview materials - the limitations}

Preview materials cannot tell students that they have the right background knowledge for a course and are limited in that respect.

\section{Diagnostic materials}

Diagnostic materials have long been used in open and distance learning to advise students about their study choices. There are essentially two kinds - generic, to test applicants' suitability for higher education and course-specific, to test suitability for a particular course. Both can be either externallyor self-assessed. In addition it is possible to argue that diagnostic materials can assess either skills or knowledge although it is not clear how easy it is to make this distinction in practice.

(a) Generic externally assessed diagnostic materials range from the massive externally assessed 194 point questionnaires such as the Noelle-Levitz test used in the US to identify vulnerable students, to the simpler test devised by Johnston at Napier University (described in Simpson 2003) used in conjunction with an interview with a student's tutor.

(b) Generic self-assessed diagnostic materials have been less used. An example is given in Simpson (2003) of a test developed from a statistical analysis of the characteristics of successful students in order to help potential students work out their predicted probability of success and see if they can change characteristics [such as low entry qualifications] which could increase their chances of success. But this has not been evaluated.

(c) Course-specific externally assessed materials where a potential student takes a test which is assessed by a member of the institution are relatively simple to design although for Open Learning institutions they may resemble entrance exams too closely for comfort. They will also be 
expensive and in trials in the UKOU where they were voluntary it quickly became clear that the potential students who submitted them were the students least likely to need to do so (Ashley 1986).

(d) Course-specific self-assessed materials appear to be more suited to mass distance education. However there are still difficult issues. It is relatively easy to design self-assessed diagnostic tests where the answers are clearly correct or incorrect as in maths science and technology subjects. It becomes more difficult where more advanced courses with some background knowledge and skills are needed such as such as courses in higher level arts or social science subjects.

It is also possible that a 'recruitment versus retention' dichotomy can occur. It can be hard for a diagnostic test writer to give 'you shouldn't be taking this course' as a possible outcome when there is pressure to recruit students onto a course. There will be a temptation to argue that a diagnostic test result should be less directive and leave the door open to students by saying something along the lines that "you will find this course a challenge unless you prepare for it carefully' instead. In one of the few evaluations of course-specific self-assessed materials Williams (2001) found that UKOU science diagnostic quizzes which used such rubrics were not as effective as she hoped in persuading students to change their course choice. But that finding may well be specific to the quizzes concerned.

Whatever the type of diagnostic material there appears to have been little work published on their effectiveness in getting students onto the correct courses. And diagnostic materials may not be sufficient in themselves as whilst they may tell a student that he or she is at the right level for a course they may not tell that student that the course has the right content for them.

\section{Conclusion}

All the methods described here for course choice have their limitations either in terms of their cost or the partial view of courses that they provide. Perhaps the best route to a satisfactory course choice system is to borrow a concept from social science - that any reality can only be fairly represented by a set of 'competing perspectives' and that a concept as complex as a course needs the perspectives of descriptions, previews, comments and diagnostic materials in order to describe it completely. How students will react to such a package of perspectives and whether it will be too much for any one student or whether different students will choose those perspectives that give them the best 'feel' for a course remains for further research.

\section{References}

1. ADAMS, C. RAND, V. AND SIMPSON, O. (1989) 'But what's it really like? - the Taster Pack Idea' Open Learning 4 (3)

2. ASHLEY, C. (1988) 'Testing the Water' internal report Open University in East Anglia

3. Clayton, P. AND McGill, P. (2000) Access issues in adult vocational guidance and counselling for people at risk of social exclusion, Journal of Access and Credit Studies 2 (1) pp 4-17

4. Johnson, M. (2000, unpublished) Course Choice Advice Open University in London internal report.

5. GiBSON, K. AND WALTERS, J. (2002) Access and guidance in tutor-student relationships Journal of Access and Credit Studies 4 (1) pp 20-31

6. MCGivneY V. (1996) 'Staying or Leaving the Course' National Institute of Adult Continuing Education, Leicester, UK.

7. Simpson, O. (2003) Student Retention in Online Open and Distance Learning RoutledgeFalmer, London

8. SimPSON, O (2002) Supporting Students in Online Open and Distance Learning ( $2^{\text {nd }}$ edition) RoutledgeFalmer, London 
9. STUdENT RESEARCh DEPARTMENT (2002), Withdrawal survey UKOU Institute of Educational Technology,

10. WILLIAMS, R. (2001) Science diagnostic quizzes in the UKOU, Internal report UKOU Science Faculty

11. YorKe M. (1999) 'Leaving Early’ Falmer Press London.

\section{Author}

Mr Ormond Simpson

Open University in the East of England 12 Hills Road

Cambridge

CB2 1PF

England

o.p.simpson@open.ac.uk 